\title{
THREE MANIFESTATIONS OF SPATIALITY IN AMBIENT MUSIC
}

\section{Richard Talbot}

Joanna Demers noted that "we are accustomed to thinking that electronic music, even more than non-electronic music, is concerned with space". ${ }^{1} \mathrm{I}$ believe this is particularly true in the case of ambient music. In this chapter, I will examine three ways in which space is manifested within the genre. In doing so, I will specifically focus my attention on Brian Eno's album Ambient 4: On Land. This is for two main reasons. Firstly, as a recording it mapped a new set of possibilities for the way ambient music could be both made and heard. The second is rather more personal, Ambient 4: On Land had a huge impact on me and ultimately inspired me to make my own music, something I continue to do nearly 40 years later.

Robert Morgan observed that "anyone familiar with the philosophical and theoretical literature dealing with music must be struck by the persistence with which spatial terminology and categories appear". ${ }^{2}$ Morgan contends that we are unable to discuss music without recourse to spatial terms, particularly when examining pitch, where "one finds it necessary to rely upon such spatially orientated oppositions as 'up and down', 'high and low', 'small and large' (in regard to intervallic 'distances') and so on. Space then [...] apparently forms an inseparable part of the musical experience”. ${ }^{3}$ Although it is worth noting that Morgan's focus is on western art music, much of what he says is equally relevant to ambient music. However, there are important differences between foregrounded music and ambient music, the latter of

1 Joanna Demers, Listening Through the Noise (New York: Oxford University Press, 2010), 113.

2 Robert Morgan, "Musical Time / Musical Space" in Critical Inquiry 6, no. 3 (1980): 527.

3 Ibid., 527. 
which is presumed to exist on the periphery of the listener's attention.

Like Morgan, Edward Campbell approaches the concept of spatiality from a realist perspective. He contends that music displays its spatiality in two 'discrete senses'. The first of these he defines as 'interior spatiality', representing the pitch continuum, the other being 'exterior spatiality', reflecting the space in which the musical performance takes place. ${ }^{4}$ This two-dimensional approach might be musicologically satisfying but it fails to take account of the way music can generate space. Jason Toynbee observes there is also a prevailing tendency (clearly visible in ambient music) in which the goal "is to create a sonic environment, a virtual dimensionality which never existed originally". ${ }^{5}$

\section{Space in music}

It is useful to think about spatiality in music as being stratified, with overlapping layers of spatiality (both musicological and non-musicological) occurring simultaneously. In order to gain a greater insight into the different forms of spatiality it is helpful to locate three areas where they reside:

1. Composition: In a compositional context, space resides in tonal texture; it can literally be found in the gaps between the notes and in the positioning of sounds in the stereo field. This is where the composer 'writes space' into the music.

2. Text: Whilst the spaces that reside in composition are innate, there are a number of ways that spatial characteristics can also be applied to music. The most common means of doing this is through the use of sound effects such as delay or reverb. It should be noted that not all of these effects have a corollary in the natural world, and we often hear performances which feature echoes and delays of far greater duration or clarity than any earthly phenomenon. It is also not

4 Edward Campbell, Music After Deleuze. (London: Bloomsbury Academic, 2013), 68.

5 Jason Toynbee, Making Popular Music: Musician's Creativity and Institutions. (London: Arnold, 2000), 70. 
unusual for several of these spatial effects to co-exist simultaneously, with several musicians utilising different spatial effects at the same time. We shall discuss this idea of applied space and its relationship with ambient music in more depth later in the chapter. There is another, more physical, way in which spatiality can be applied. Campbell describes it as 'exterior spatiality', the audio recording of specific spaces such as concert halls and stadiums or the use of field recordings. Live albums frequently exemplify this where we hear music physically enshrining the sonic properties and artefacts of the venue the music was recorded in.

3. Psychological space: The product of the listener's interaction with sound or music, taking account of factors like memory, perception, temporality and imagination. For example, when writing about Trance Music, journalist Heinrich Deisl devised the term fluchtpunkt to describe "a space in nowhere that can be filled with all your ideas, projections, dreams, hopes, imaginations. It is not connected to reality at all. A simulation". ${ }^{6}$ In the liner notes to the second edition of Ambient 4: On Land, Eno recounted how he created a perceptual space. While travelling in Ghana, he had used a stereo microphone "placed to pick up the widest possible catchment of ambient sounds from all directions, and listening to the result on my headphones. The effect of this simple technological system was to cluster all the disparate sounds into one aural frame; they became music" ${ }^{7}$

Whilst it is clear that spatiality is present in different ways across all musical experiences I want to consider some ways in which we can see notions of space at play within ambient music.

\footnotetext{
6 Finn Cohen, In Defence of Trance, accessed June 1, 2018, https://pitchfork.com/features/article/indefense-of-trance/

7 Brian Eno, liner notes from Ambient Music 4: On Land. (London: E.G. Records, 1986).
} 
The first category is ubiquitous to all musical experiences, irrespective of genre. Doyle ${ }^{8}$, describes it as listening space, and Demers defines it as "a composite of the perceived spatial characteristics of a work usually in recorded form, as well as the emotions that those characteristics elicit from the listener". ${ }^{9}$ The notion that sound can be a vehicle to convey spatial characteristics corresponds with Smalley's assertion that sounds carry their own space, acting as "space bearers". ${ }^{10}$ While the interaction between the listener's knowledge, preconceptions and the music provides an excellent framework for understanding how listening space is constructed, I believe that we should also take into account the role of the listening environment. I suggest that listening space is formed from a triangulation of three elements: listener, music and environment. As listeners, we tend to be very sophisticated about the ways we manage this set of relationships - even unconsciously so. This is illustrated in the way that we employ specific music in a wide variety of situations such as driving, studying or dining. It is likely that we would choose different pieces of music to enhance our experience of each of these scenarios. The listening spaces we create are unique and irreproducible by virtue of the complex factors and interactions involved in their construction. Firstly, each individual's experience and knowledge are unique; this alone ensures that no two people mediate a listening space in the same way. Secondly, listening environments constantly change. Although the differences between separate manifestations of a listening space may, at times, be imperceptible, there will always be some variation - no matter how slight. As we have noted, listening space is present in all musical experiences regardless of genre, however, it is worth noting that ambient music in its first iteration was consciously designed as a form of environmental control to configure the relationship between listener, environment and music. In the liner notes to Music for Airports, Eno makes this explicit declaring that:

8 Peter Doyle, Echo and Reverb (Middletown CT.: Wesleyan University Press, 2005).

9 Demers, Listening Through the Noise, 116.

10 Denis Smalley. “Space-Form and the Acousmatic Image," Organised Sound 12(1), (2007): 38. 
An ambience is defined as an atmosphere, or a surrounding influence: a tint. My intention is to produce original pieces ostensibly (but not exclusively) for particular times and situations with a view to building up a small but versatile catalogue of environmental music suited to a wide variety of moods and atmospheres. ${ }^{11}$

The second manifestation of space in ambient music is best described as 'manufactured space'; similar to listening space, it is nearly ubiquitous to all forms of recorded popular music. Earlier, we looked at the use of spatial effects to manufacture simulations of real or imaginary spaces. Such use of effects can be broadly delineated into two main categories: 'applied' and 'embodied'. The former includes effects such as delay or reverb that can be added to an instrumental part in order to simulate space, distance or atmosphere. A guitar that was actually recorded in a cellar can, with the judicious use of reverb, be made to sound as if it were being played in a cathedral. This process is additive in that spatiality is literally 'added to the music' at some point between recording and creating a final mix. This is the most prevalent way that effects are utilised in popular music. Embodied effects, however, are a constituent part of the music, and are integral to the rhythmic, melodic or harmonic structures of a musical text. A prime example might include the tape delay system employed by Brian Eno (and subsequently Robert Fripp) to create Discreet Music. ${ }^{12}$ Two short melodic fragments were fed into a long delay system created by linking two tape recorders. ${ }^{13}$ This resulted in a constantly evolving bed of sound generated from a limited musical input. Another commonly heard example is the use of multiple delays to generate complex rhythmic patterns. In these instances, the effects are no longer just a

11 Brian Eno, “Ambient Music”, liner notes for Ambient Music 1: Music for Airports. (London: E.G. Records, 1978).

12 Brian Eno, Discreet Music. (Obscure / Island Records, 1975).

13 More information on this delay system, can be found in the Discreet Music sleeve notes along with an informative diagram. 
'treatment' of sound suggesting distance or presence, rather they are actually embodied in the music, generating rhythmic and sonic attributes.

There is a secondary type of embodiment that should also be acknowledged. Distinct sonic attributes are often associated with individual pieces of technology. These place a sound in terms of cultural association or previous musical use. A prime example of this is the Roland Space Echo. Originally introduced in 1974, it was an extremely popular tape delay unit used by countless artists from different genres and musical generations including: King Tubby, Pink Floyd, The Orb and Brian Eno. The Space Echo was noted for its characteristic 'warm sound' as well as its subtle tape flutter. Although Roland ceased manufacturing them in 1990 (they currently make a foot pedal which simulates the original Space Echo's effects) some original units and a wide variety of modern hardware and software simulations are still in widespread use. This is not because they offer an authentic simulation of space, rather it is because the sonic artefacts of the device are associated with a host of classic and vintage recordings. Effectively, the Space Echo is used as a carrier of sonic information about time and technology.

We tend to think of the use of effects as being a technologically-assisted process. However, we should remember that musicians have always found ways to sonically manipulate playing environments in order to enhance their sound. Doyle ${ }^{14}$ recounts an anecdote about Robert Johnson playing into the corners of rooms to achieve a specific sonic effect. Similarly, as we noted previously, certain environments such as places of worship or purpose-built concert halls have been created specifically for their acoustic properties. A number of musicians from different musical backgrounds have sought out places with particular or unique acoustic properties and assimilated the resonances and sonic properties of those spaces into their music. New Age flautist Paul Horn recorded in a number of exotic spaces including the Taj Mahal and the Great Pyramid, while Pauline Oliveros performed in a hugely reverberant underground cistern.

14 Doyle, Echo and Reverb. 
The third type of space I wish to discuss could be classed as a type of 'figurative space' and is more specific to the generic conventions of ambient music. This manifestation of space occurs where elements of representation and simulation meet. Unlike the aforementioned examples of spatiality, figurative space is not part of any mechanical, acoustic or technological process. Rather, it is the product of artistic construction, and its purest iteration is found in pieces of music that model or represent real or imagined places or natural phenomena.

Between 1978 and 1982 Brian Eno oversaw the release of a series of four stylistically different records ${ }^{15}$ that laid out various templates for ambient music. While the first three albums in the series featured relatively conventional tonal and harmonic material, Ambient 4: On Land approached the idea of making ambient music from a completely different direction. Eno stated that the album was "an attempt to transpose into music something that you can do in painting: creating a figurative environment" ${ }^{16} \mathrm{He}$ explained that:

What qualified a piece for inclusion on the record was that it took me somewhere, but this might be somewhere that I'd never been before, or somewhere I'd only imagined going to. Lantern Marsh, for example, is a place only a few miles from where I grew up in East Anglia, but my experience of it derives not from having visited it (although I almost certainly did) but from having subsequently seen it on a map and imagining where and what it might be. We feel affinities not only with the past, but also with the futures that didn't materialise, and with the other variations of the present that we suspect run parallel to the one we have agreed to live in. ${ }^{17}$

15 The albums in the Ambient series were: Brian Eno - Ambient 1: Music for Airports, Harold Budd and Brian Eno - Ambient 2: The Plateaux of Mirror, Laraaji - Ambient 3: Day of Radiance (Produced by Brian Eno), Brian Eno - Ambient 4: On Land.

16 Brian Eno, liner notes for Ambient Music 4: On Land (London: E.G. Records, 1978).

17 Ibid. 
In light of this, it is tempting to view Ambient 4: On Land as a protohauntology record (albeit one that pre-dates Derrida's use of the term by more than ten years). Eno's suggestion of nostalgia for lost futures is also a recurring theme in hauntological discourse. Mark Fisher notes that:

In hauntological music there is an implicit acknowledgement that the hopes created by postwar electronica or by the euphoric dance music of the 1990s have evaporated - not only has the future not arrived, it no longer seems possible. Yet at the same time, the music constitutes a refusal to give up on the desire for the future. ${ }^{18}$

Proponents of hauntology contend that it is impossible to fully recreate (or resurrect) the past but spectral versions of it infiltrate the present. However, while Ambient 4: On Land shares the hauntologist's preoccupation with the past, and particularly the potential futures that it seemingly offers, there are differences in methodology. Hauntologists generally signify the past by assimilating its musical conventions and technologies into their present day music. On occasion these musical devices even become part of the artist's signature sound, regularly reappearing throughout their catalogues, including: tape flutter (Boards of Canada), disembodied and ghostly voices, (Burial), and analogue synthesis reminiscent of 1970s TV themes (Belbury Poly, The Focus Group). On Land, Eno's exploration of memory and lost futures, took a completely different route. During the recording process, Eno gradually abandoned traditional notions of musicology, preferring to draw on his training as a visual artist ${ }^{19}$ and to adopt a more painterly approach to sound in order to evoke the ghosts or presence of place:

18 Mark Fisher, Ghosts of My Life. Writings on Depression, Hauntology and Lost Futures (Winchester: Zero Books, 2013), 21.

19 Eno studied at Winchester School of Art from 1966-69. 
As I made these pieces, I began to take a different attitude towards both the materials and the procedures I was using. I found the synthesiser, for example, of limited usefulness because its sound tended towards a diagrammatic rather than an organic quality. My instrumentation shifted gradually through electro-mechanical and acoustic instruments towards non-instruments like pieces of chain and sticks and stones. ${ }^{20}$

So, does this idea of constructing space within the confines of ambient music work any differently than in other forms of popular music? Giacomo Botta notes that:

Popular music is as much about places as it is about sounds. Its production is forged in studios, rehearsal areas and bedrooms, places often mythologized in popular music history. Popular music is also recorded using studio techniques designed to recreate space, through reverb and other effects. Its collective consumption happens in concert halls, clubs and bars while its individual consumption takes place in streets, homes and at bus stops; all physical places. In addition, popular music often represents or sounds like certain urban or rural, real or imagined places of various scales. ${ }^{21}$

Certainly, rock and pop records over the last 60 years have generally attempted to replicate the audio dynamics of live performance. Typically, the vocal is foregrounded and supported by the other instruments each of which occupies a sonic space supposedly reflecting their on-stage positioning. Ambient music, however, rejects these conventions by removing the foreground and

20 Brian Eno, liner notes for Ambient Music 4: On Land (London: E.G. Records, 1978).

21 Giacomo Bottà, "Unsichtbare Landschaften: Populäre Musik Und Räumlichkeit / Invisible Landscapes: Popular Music and Spatiality." April 12, 2016. Accessed June 1, 2018. https://giacomobotta. wordpress.com/2016/04/12/unsichtbare-landschaften-populare-musik-und-raumlichkeit-invisiblelandscapes-popular-music-and-spatiality/. 
cuts itself loose from the spatial configurations of popular music, creating a decentralised sound field that solidifies the notion of space rather than those who occupy it.

Botta's contention that popular music frequently represents real or imaginary spaces is somewhat more problematic than it might at first appear. Let us consider "Waterloo Sunset" by The Kinks ${ }^{22}$. On the surface, the song seems to capture a sense of place, nostalgia and yearning beautifully. However, 'place' only exists as a backdrop for the singer and his concerns. In this case, place is reduced to context and consequently the listener is always one step removed from it, as they can only experience it via the singer and their persona. The singer demands our attention, s/he always distracts us from the musical accompaniment. If the listener wanted to explore the place in the record, they would have to achieve the impossible and somehow find a way to listen through, or around, Ray Davies. As Eno noted: "Take a landscape. As soon as there is a human subject, however tiny, it captures all the attention". ${ }^{23}$ Ambient music removes itself from the foreground and sheds the focal point of singer or instrumentalist. This leaves us with a very different audio topography, in which a new sonic landscape, one without a central focus, becomes part of the genre's expressive vocabulary.

\section{Representation and simulation}

The methodology used to construct figurative spaces in ambient music draws on a combination of elements associated with representational art and simulation. However, the idea that music itself can be representational

22 "Waterloo Sunset" was released as a single in 1967, reaching number 2 in the UK singles chart.

23 Franck Mallet, "Redefining Musical Space: In the Enosphere," Artpress, 271, (2001), accessed January 18, 2018, http://music.hyperreal.org/artists/brian_eno/interviews/artpress01.html 
has been contested by various writers. Nelson Goodman ${ }^{24}$, Roger Scruton ${ }^{25}$ and Richard Kuhns ${ }^{26}$ all express widely differing opinions that are heavily mediated by factors such as connotation and denotation. Scruton flatly asserts that:

Music may be used to express emotion, to heighten a drama, to emphasise the meaning of a ceremony; but it is nevertheless an abstract art, with no power to represent the world. Representation, as I understand it, is a property that does not belong to music. ${ }^{27}$

This is a complex debate which is too involved to be thoroughly explored here. However, regardless of this ongoing debate, ambient music certainly meets some of the conditions that Scruton deems necessary for artworks to be considered representational. For example: the use of compositional titles, clearly indicating the nature of the subject to provide a framework through which listeners are guided in a specific way. Ambient 4: On Land, for example, features several pieces whose titles reference specific geographical locations including, "Lantern Marsh", "Leeks Hills", and "Lizard Point”. Kendall Walton suggests that "mere titles often suffice to make music patently representational; indeed I cannot imagine music which an appropriate title could not render representational". ${ }^{28}$ Many ambient works feature direct representations of the subject. In the case of musician Simon Scott, he included field recordings of the Cambridgeshire Fens which were also the

24 Nelson Goodman, Languages of Art, An Approach to a Theory of Symbols. (Indianapolis and New York: Bobbs-Merrill, 1968).

25 Roger Scruton, “Representation in Music," Philosophy 51 no.197 (Cambridge: Cambridge University Press, 1976): 273-287.

26 Richard Kuhns, "Music as a Representational Art," The British Journal of Aesthetics, 18 no.2, (1978), accessed January 18, 2018, https://doi.org/10.1093/bjaesthetics/18.2.120

27 Scruton, "Representation in Music."

28 Kendall Walton, "Listening with Imagination: Is Music Representational?" The Journal of Aesthetics and Art Criticism, vol. 52, no.1, The Philosophy of Music (1994): 47. 
subject of his 2012 album Below Sea Level. ${ }^{29}$

I wanted to combine organic recordings and synthetic sounds. I'd go out into the Fens and record with hydrophones underwater and other microphones on or above the surface of the water [...] The hard part was to blend actual recordings with digitally processed sounds so that it never becomes too synthetic and loses the character of the Fens. ${ }^{30}$

Scott's music relates to the landscape at all stages of creation:

I use a portable speaker to mix outside so at that point, when I think a track is almost complete, I go out into my sweet sounding location in The Fens and set up microphones to capture a mix being played out into that environment. It works for my music and I love the collaborative results from doing this. ${ }^{31}$

However, the use of field recordings does not have to be so literal in order to be representational; imitative or even borrowed sounds can be equally effective. While Eno's On Land album is ostensibly located in East Anglia, it features sounds collected from other locations. The frogs prominently heard on "Unfamiliar Wind (Leeks Hills)" were actually recorded in Choloma, Honduras. After all, we would not expect a landscape painter to be reliant on materials sourced from the site they were painting.

Intertwined with these aspects of representation, simulation also plays an important role in the way figurative space is manufactured. In 2009 my duo

29 Simon Scott, Below Sea Level (New York: 12K - 12k1071).

30 “Exclusive Interview with Simon Scott," (2013), http://sonicfield.org/2013/10/exclusive-interviewwith-simon-scott/

31 In the studio with Simon Scott, 2015, https://reviews.headphonecommute.com/2015/10/22/in-thestudio-with-simon-scott/ 
Marconi Union made an album inspired by Tokyo. ${ }^{32}$ However, neither of us had ever visited the city. Our only experience of Tokyo was through received images in books, films and television. I would argue that the record we made was an example of simulation which Jean Baudrillard ${ }^{33}$ or Umberto $\mathrm{Eco}^{34}$ might recognise, in which reality is eroded by media. It also demonstrates that authenticity is not a necessary component of figurative space. This strand of constructing fictional, or what I prefer to call 'unexperienced', places, is prevalent in ambient music. There are numerous ambient works exploring science fiction themes such as outer space ${ }^{35}$ - environments we can safely assume are unfamiliar to the artists who created them. Yet, despite this, they can still resonate with us as listeners, because the preconceptions on which they are built, whether based on media images (like our album Tokyo) or some other source, are shared by both artist and listener. Ultimately, it is possible that we are more likely to recognise the simulation than the reality. As listeners we have developed an extensive repertoire of sonic signifiers. These connote these unexperienced places in a way that is commonly understood by listeners and artists. There are, for instance, lots of sounds that have only existed in science fiction films and television but which are widely recognisable, such as the lightsaber from Star Wars or the Dalek's voice from Doctor Who.

Simulation occurs both conceptually and also as a sonic component within pieces of music. Anyone who has spent any time listening to ambient records will have heard tracks featuring the sounds of cicadas, birdsong, wind or rain. These sounds, or synthetic approximations of them, can be easily obtained from a sound library, created with a synthesiser or sampler and inserted into a

32 Marconi Union, Tokyo (BineMusic BINE 020CD, 2009).

33 Jean Baudrillard, Simulations, trans. Paul Foss, Paul Patton and Philip Beitchman (New York: Semiotext(e), 1983).

34 Umberto Eco, Travels in Hyperreality The fortress of Solitude (London: Picador, 1987).

35 Many 'ambient' artists such as Brian Eno, The Orb and Biosphere have made music inspired by science fiction themes. 
piece of music. Our fluency in decoding them and their connotations makes them extremely effective at simulating locations and environments.

This opens up a number of questions about transmission and reception, and how we interpret records that represent place. Eno writes that the piece "Lantern Marsh", featured on his album Ambient 4: On Land, was inspired by seeing the place name on a map, rather than any actual memories of visiting it, although Eno acknowledges that he almost certainly did.

He also contends that, "we feel affinities not only with the past, but also with the futures that didn't materialise, and with the other variations of the present that we suspect run parallel to the one we have agreed to live in". ${ }^{36}$ So, how do we understand this piece? First, we have a place constructed by an artist. This place is at a junction of knowledge, temporality and imagination or creativity. Eno is engaged in creating a version of his own past and a geography of a place that may or may not have existed. However, this is a 1982 'version' of "Lantern Marsh". So, are we hearing Eno as an adult, or Eno as a child imagining Lantern Marsh? Is this a place that can be found on a map, or is it imaginary, like Marconi Union's depiction of Tokyo? Does it even exist at all? Is it just a metaphor for memory and loss? Or is it just a name applied to a piece of music in order to give it meaning? It could possibly be all these things, some of them, or none. Even for the composer the meaning of a given title may not be fixed. Perhaps the most important question is: how does this relate to the listener? When they hear this music, what are they engaging with? Is it the depiction of Eno's memory, something they could not possibly have experienced - especially as it is not at all clear that Eno has any such memories with which to engage? Or is the music a vehicle for them to project their own experiences and memories onto as part of their listening space? As we grow up, we all inevitably accumulate our own unrealised futures, dreams and hopes that were not realised. These are our own Lantern Marshes, and they are precisely that, our own. Their personal nature ensures that they remain, for the most

36 Eno, liner notes for Ambient Music 4: On Land. 
part, unshareable. We should also consider that the transmission of meaning is a two-way process between the listener and the artist.

It is necessary to sound a note of caution here, due to the fact that every musician has their own approach to making music. While some are keen to engage with the conceptual underpinnings of the area they choose to work in, others prefer to think about music solely in terms of form. Equally, we should bear in mind that not all compositions that appear to be representational are necessarily created with a specific subject in mind. Often, this process works in reverse: rather than making a piece of music that represents a specific object, the artist attaches meaning to an existing piece. They complete a track before deciding on a title that they feel reflects the music. In this situation, the artist occupies two positions: they are both creator and listener, divining meaning and imagery from the music but without the benefit of the titular cues that would normally be present for the listener.

\section{Conclusion}

As has been shown from the discussions about listening space and manufactured space, spatiality is innate to all areas of music, regardless of genre. However, ambient music, through its generic conventions and affordances, presents particular ways of creating imagined, embodied and representational space. In the case of Ambient 4: On Land (and many other ambient records), this space revolves around temporal disjunction, with the composer using place as a metaphor for memory and loss.

There is one last temporal disjunction overlaying all those previously discussed. Ambient 4: On Land, Eno's meditation on lost pasts and futures, is itself receding further into the past, and is now older than Eno was when he first released it. However, over the intervening years the album has informed numerous ambient recordings and even entire sub-genres, such as dark ambient, and its influence, particularly the idea of creating figurative space, is still very much present today. 